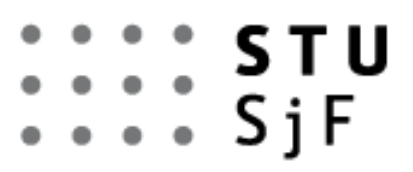

盟

DE GRUYTER OPEN

\section{Journal of MECHANICAL ENGINEERING - Strojnícky časopis}

VOLUME 66, NO 2, 2016

pp. $23-28$

DOI:10.1515/scjme-2016-0015

\title{
FORCE ANALYSIS OF BENCH PRESS ON STABLE AND UNSTABLE BASE
}

\author{
HUČKO Branislav', ČEKAN Michal², HORVÁT František ${ }^{3}$ \\ ${ }^{1}$ Slovak University of Technology in Bratislava, Faculty of Mechanical Engineering, Institute of Applied \\ Mechanics and Mechatronics, Nám. slobody 17, 81231 Bratislava, Slovakia, e-mail: branislav.hucko@stuba.sk \\ ${ }^{2}$ Slovak University of Technology in Bratislava, Faculty of Mechanical Engineering, Institute of Applied \\ Mechanics and Mechatronics, Nám. slobody 17, 81231 Bratislava, Slovakia, e-mail: michal.cekan@stuba.sk \\ ${ }^{3}$ Slovak University of Technology in Bratislava, Faculty of Mechanical Engineering, Institute of Applied \\ Mechanics and Mechatronics, Nám. slobody 17, 81231 Bratislava, Slovakia, e-mail: frantisek.horvat@stuba.sk
}

\begin{abstract}
The contribution reviews current technologies for the measurement of performance in athletes during stationary exercise and validates the technology utilizing accelerometry. The behaviours of force during the bench press exercise on a stable and unstable base are reviewed and the results are presented. It was found that, training on an unstable base can be exploited by athletes to maximize their performance.
\end{abstract}

KEYWORDS: Bench-press, accelerometry, impulse, performance, training

\section{Introduction}

Common methods for determining performance parameters of athletes are based on the simple principles of Newton's second law. Common systems consist of a mechanical sensor which measures velocity of a rotating disk to derive the force characteristics. These mechanical systems typically require physical attachment to the moving element of the exercise (in the case of the bench press, the bar or weight). The bench press exercise on a stable base (bench) can be easily characterized using these systems alone (FiTRO Dyne Premium) [1]. However, it becomes more difficult to implement when exercising on a swissball (flexible base). The main problem is that the characteristic of the concentric phase are no longer accurate since the swissball deforms relative to the weight and thus the pressing characteristic of the athlete. Due to this limitation of mechanical measuring systems, a direct comparison of performance parameters cannot be made with classical bench press since the results do not incorporate the characteristics (movement) of the swissball. The problem is that it is difficult to identify why some athletes have better results on the swissball as opposed to the classical bench press, and vice versa. In order to overcome this problem it was necessary to implement two analog accelerometers to capture the characteristics of both the weight being pressed, as well as the deformation of the swissball itself.

\section{Apparatus}

The accelerometers utilized in the measurements were tri-axial ADXL 325 accelerometers capable of high accuracy within a range of $\pm 5 \mathrm{~g}[2,5]$. Analog accelerometers were used to ensure high resolution and response of the data being captured. A comparison of the acceleration data captured from the mechanical disk system (FITRO) and the ADXL accelerometers (IMU) can be seen in figure 1 . 
FTVS,STU

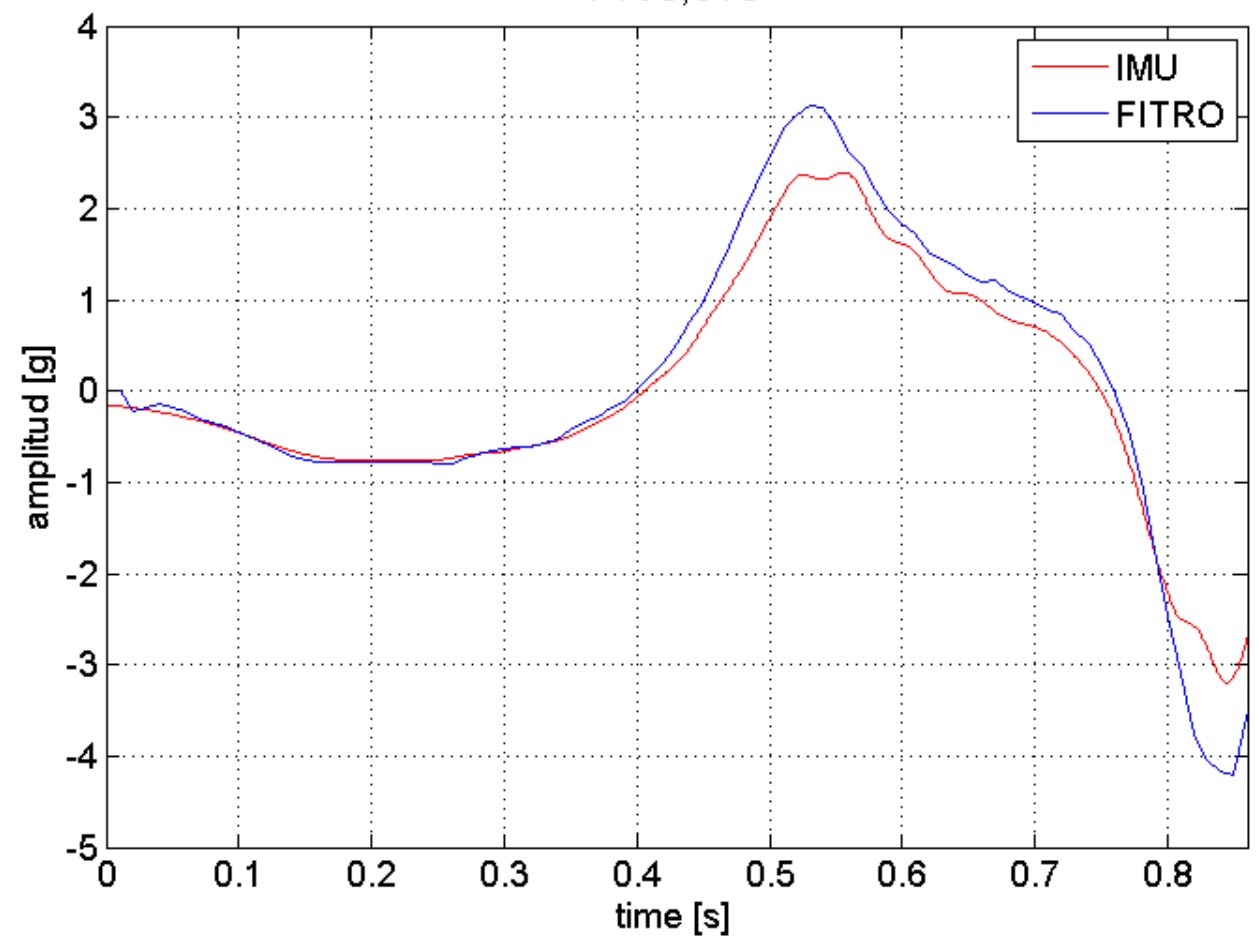

Fig. 1 Comparison of acceleration results with mechanical FITRO and IMU systems.

The data acquisition is setup to sample at a rate of $1 \mathrm{kH}$ in order to obtain a robust set of data. An accelerometer is mounted on the center of the bar which holds the weights. The second accelerometer is placed on the athlete's trunk in order to capture the accelerations of the athlete's body. The accelerometers measure synchronously and the captured voltage data are then post-processed in the MATLAB software environment where signals on the swissball and bar were compared with each other.

\section{Classic benchpress characteristic}

Before the characteristics which affect a bench press on an unstable base can be understood, it is necessary to first understand the characteristic of the typical bench press exercise (on a stable base). Referring to the acceleration characteristic in Figure 2 the start point of the bench press cycle can be defined as the moment the athlete begins to drop the weight towards their chest. At this moment the muscles relax and allow gravity to overcome the athletes resistance to the weight, allowing it to move downward toward their chest, hence the drop in acceleration in the eccentric phase. As the weight continues downward, the athlete begins to reintroducing resistance, thus slowing down the weight, indicated by the inflection point of the local minimum in the eccentric phase (this usually occurs when the athlete's forearms are at approximately $90^{\circ}$ relative to their biceps). In figure 2 it can be seen that the acceleration (resistance) continues to rise as the athlete must overcome gravities effect on the weight until it stops its downward motion completely (global maximum). At this point the athlete is introducing more energy into the system to begin pushing the weight in the opposite direction (upward, concentric phase). As the weight continues upward (when the athlete passes the approximate $90^{\circ}$ forearm to bicep position) the acceleration slightly stabilizes until the elbows lock and the acceleration once again sharply changes its character until the global minimum is reached. This explanation can represents the full bench press cycle, where the concentric phase approximately starts from the global maximum and finishes at the global minimum in Figure.2. 


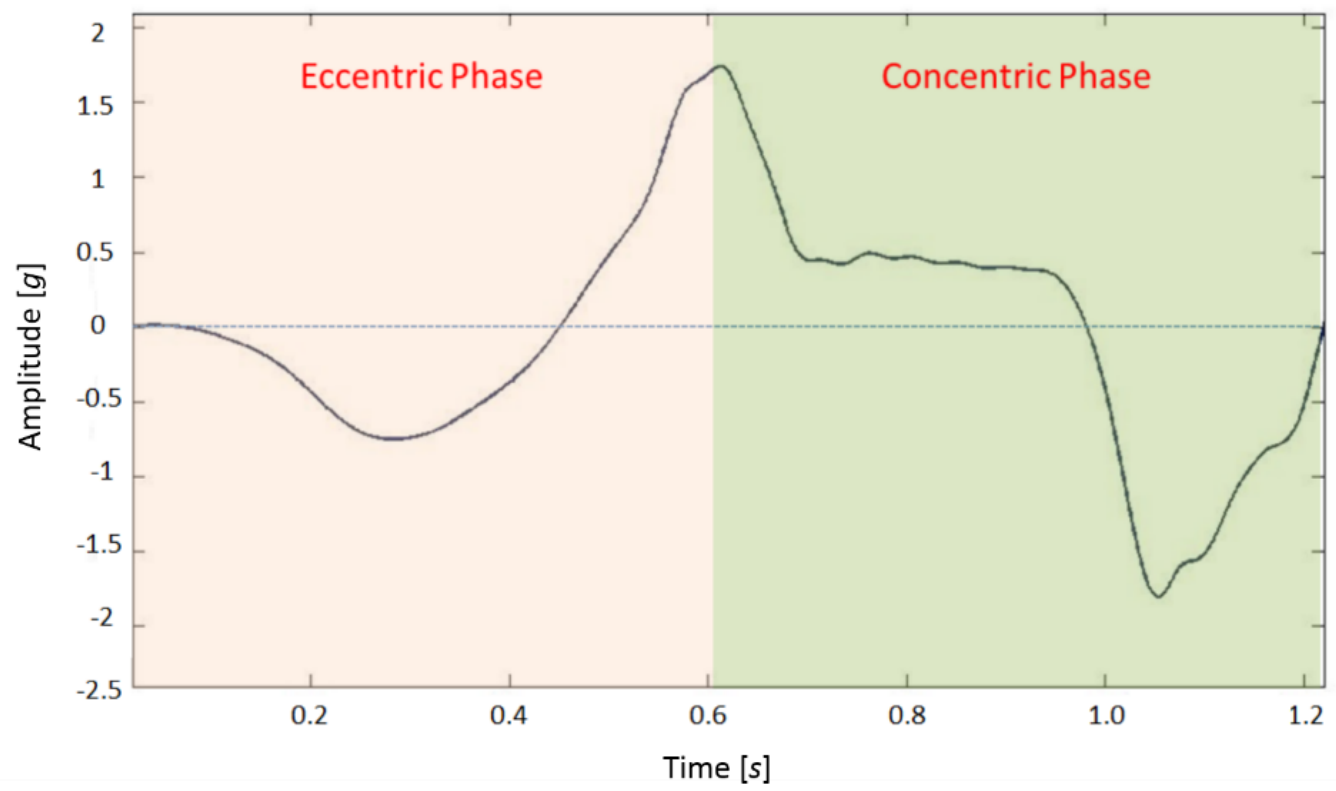

Fig. 2 Typical bench-press acceleration characteristic (stable base)

\section{Benchpress on an unstable base}

In the classical bench press the acceleration behaviour of the bar can be observed in Figure 2 . Due to the rigidity of the bench itself, the athlete's body does not significantly accelerate in the vertical direction and the acceleration character of the bar itself is sufficiently accurate in determining performance parameters of the athlete. However an obvious double peak character can be observed on the accelerometer mounted on the athlete when the bench press is performed on an unstable base (swissball), see figure 3. This characteristic is key in presenting the effects of the swissball on the athlete.

As seen in Figure 3, the acceleration characteristic of the bar are similar to that in Figure 2, however the accelerometer on the trunk of the athlete indicates a unique character of acceleration. Going through the bench-press cycle again, as the athlete begins to reintroduce resistance against the downward motion of the bar (approximate $90^{\circ}$ bicep to forearm position) the swissball begins to compress, where it acts as an elastic support for the athlete in the eccentric phase. After initial compression, the swissball slightly springs back, but momentum of the weight causes the swissball to compress further until the beginning of the concentric phase. At this point the swiss-ball releases its energy back onto the athlete's trunk, and consequently the weight. At the approximate $90^{\circ}$ forearm to bicep position, the athlete begins to introduce more energy into the system and the swiss-ball once again compresses under the combined effects of the accelerating weight as well as the weight of the athlete. This is identified by the sharp and opposite acceleration character on the trunk with respect to the bar. The elbows then lock and the cycle has finished, however the athlete and weight continue to oscillate on the swissball until both stabilize. 


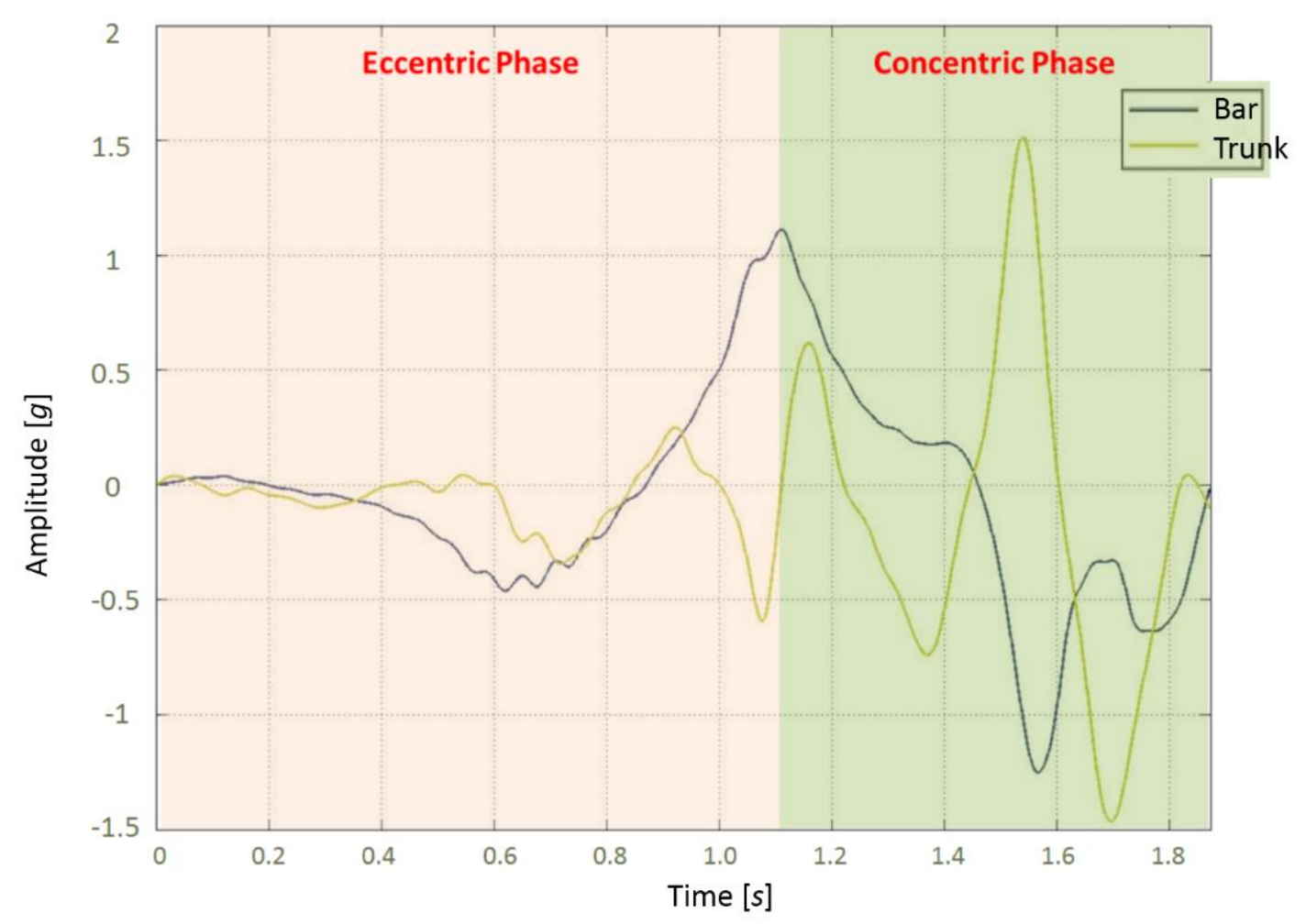

Fig. 3 Trained athlete performing bench-press on an unstable base (swissball)

\section{$4 \quad$ Force analysis}

The interpretation of the concentric phase can also be quantitatively understood by other variables such as force impulse. In general, impulse is defined as the vector response over the duration of the impulse, which in integral form is written as:

$$
\bar{I}=\int_{t_{1}}^{t_{2}} \bar{F}(t) d t,
$$

where: $\bar{I}$ is the impulse, and can be described in figure $4, \bar{F}(t)$ is the time-dependent force, and $t_{2}, t_{1}$ are the time boundaries of the concentric phase.

From the aforementioned relation the time interval must be defined to obtain the force impulse, this is found as the duration from the beginning to the end of the concentric phase of the bench-press. It is obvious that the duration of the concentric phase is different for each repetition, thus it is more appropriate to substitute the entire impulse with a unit of impulse per time. The idea is that a higher value of unit impulse indicates a shorter duration in the concentric phase, which consequently may indicate an increase in the athletes performance. The unit impulse can then be defined by the following relation (2).

$$
I_{w}=\frac{\int_{t_{1}}^{t_{2}} F(t) d t}{t_{2}-t_{1}}
$$

Fig. 4 represents the average unit impulse on the bar of 3 athletes performing the bench press at $70 \%$ of their one rep. maximum on a stable and unstable base. 


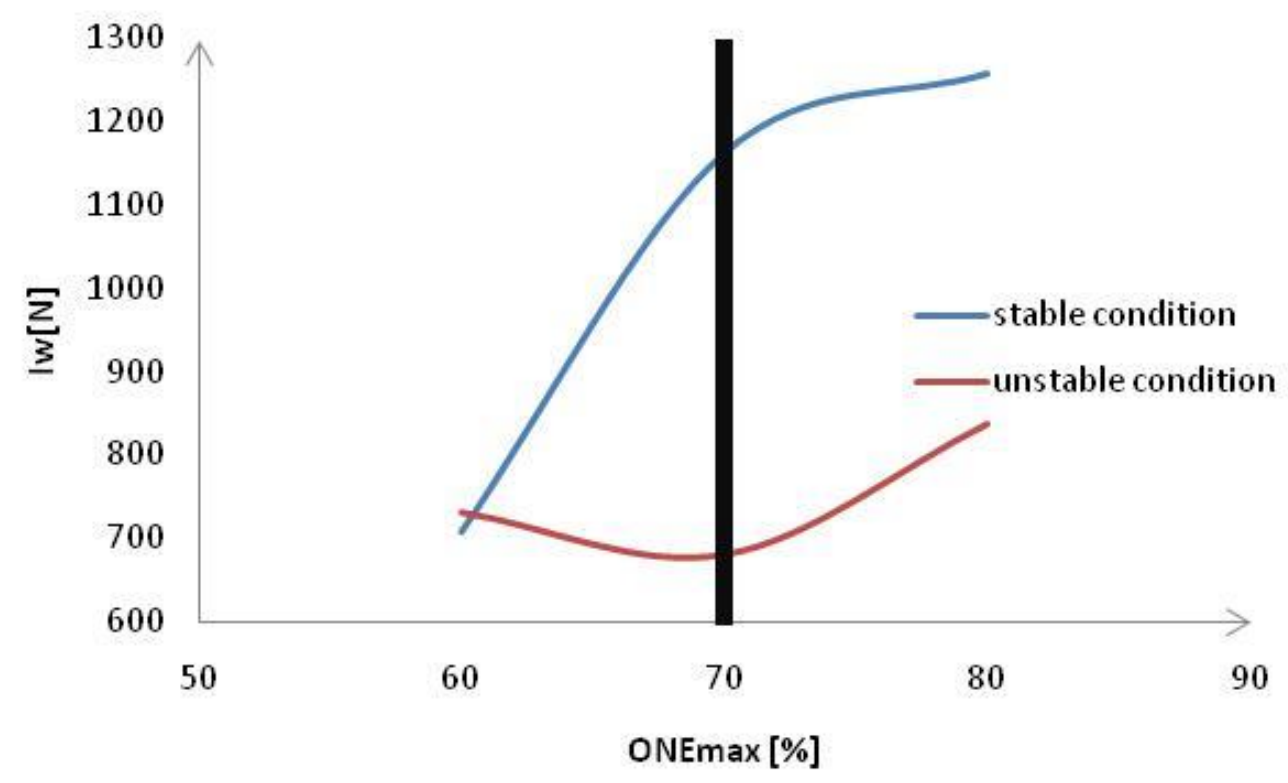

Fig. 4: Unit force Impulse - comparison

\section{DISCUSSIONS AND CONCLUSIONS}

The athlete can utilize the stored energy in the swissball from the eccentric phase to help lift the weight at lower positions (less than $90^{\circ}$ forearm to bicep angle). The athlete can also take advantage of the swissballs deformation (compression) when pushing past the $90^{\circ}$ forearm to bicep position. This effectively compresses the ball in the opposite direction that the weight is traveling, alleviating some of the energy required to push the weight upward. A well-coordinated athlete was capable of exploiting the swissballs deformation and response in the transition from eccentric to concentric phases and after the $90^{\circ}$ forearm to bicep position (in concentric phase). However less stable athletes displayed difficulties performing the bench press cycle on an unstable base, not being able to exploit the deformation characteristics of the swiss ball.

The force impulse comparison in figure 4 considers the energy of the bar in the bench press cycle, however it is obvious from figure 3 that the motion of the trunk should also be similarly characterized in order to obtain a true representation of the energy generated by the athlete. Further study should incorporate the trunk into the force impulse calculations

For clarity, acceleration results in figures 1, 2, and 3 show the acceleration of the bar in space and neglect the contribution of gravity while the impulse calculations consider the effects of gravity.

In conclusion, effective use of accelerometers can provide a more detailed description of a given exercise compared to standard methods [1], provided that their implementation properly captures the motions involved. Furthermore, correct interpretation of the accelerometer results are integral for the accurate quantification of force, impulse, and energy.

\section{Acknowledgements}

The paper was supported by the grant from Grant Agency of VEGA no. 1/0712/14 entitled " Micro-electromechanical system (MEMS) of energy accumulation for medical usage ". 


\section{REFERENCES}

[1] Fitronik s.r.o., FiTRO Dyne Premium. Principles. Available on the web: $<$ www.fitronic.sk> (2012)

[2] Analog devices., ADXL325. MEMS accelerometers. Available on the web: $<$ www.analog.com> (2016)

[3] Hibbeler, R.C.: Engineering Mechanics: Dynamics. 14th Edition. Prentice Hall. 2015, pp. 237-240, ISBN 0133915387

[4] Hučko B., Čekan M., Horvát F.: Force analysis in hip joint using simulation and measuring. 11th Pan-American Congress of Applied Mechanics, 2010, ISBN 978-8585205-97-3

[5] GOGA V., HUČKO B.: Phenomenological Material Model of Foam Solids. In Journal of Mechanical Engineering - Strojnícky časopis, Vol. 65, No. 1, 2015, pp.5-20, ISSN 00392472 